\title{
Influence of Irrigant Solutions and Apex Locators in Working Length Determination
}

\author{
Reynoso $\mathrm{RF}^{1}$, Nazario $\mathrm{RN}^{2}$, Rodriguez J ${ }^{3}$, Bittencourt $\mathrm{BF}^{4}$, Dominguez $\mathrm{JA}^{5^{*}}$ \\ ${ }^{1}$ Student, Department of Endodontics, Faculty of Health Science, Norbert Wiener University, Lima, Peru \\ ${ }^{2}$ Professor, Department of Endodontics, Faculty of Health Science, Norbert Wiener University, Lima, Peru \\ ${ }^{3}$ Professor, Sp Department of Endodontics, Faculty of Health Science, Norbert Wiener University, Lima, Peru \\ ${ }^{4}$ Professor, PhD, Department of Dentistry, State University of Ponta Grossa, Ponta Grossa, Brazil \\ ${ }^{5}$ Professor, PhD, Department of Endodontics, Faculty of Health Science, Norbert Wiener University, Lima, Peru
}

*Corresponding author: Dominguez JA, Department of Endodontics, Faculty of Dentistry, Wiener Norbert University, Lima, Peru, Tel: 51-949725704, Email: johnalexis.dominguez@gmail.com

Citation: Reynoso RF, Nazario RN, Rodriguez J, Bittencourt BF, Dominguez JA (2017) Influence of Irrigant Solutions and Apex Locators in Working Length Determination. J Oral Health Dent Sci 1: 103

Article history: Received: 07 December 2016, Accepted: 23 January 2017, Published: 25 January 2017

\begin{abstract}
The objective of this study is to evaluate the accuracy of three apex locators using four irrigant solutions to determine the working length of root canals. Material and methods: thirty unirradicular teeth were used. Teeth were randomly divided into three groups, in order to establish the working length, using different apex locators: Raypex 6, Endo EZE and RootOR. Four different irrigant solutions were used combined with the apex locators: saline solution ( $0.9 \%$ sodium chloride), $2 \%$ chlorhexidine digluconate, 18\% EDTA and 5.25\% NaCLO. Real working length (RWL) was determined using a \#15 K-file in each specimen until the end of the file was visualized in stereoscopic microscopy. Scores (\%) were attributed to each difference found between the working length gave by the apex locators and the RWL. Results: there was a significant difference between the RWL and that one found with the apex locators Raypex 6 and RootOR; however, Endo EZE did not show statistical differences. The four different irrigant solutions did not show statistically differences between then. Conclusions: the precision to estimate the working length with Raypex 6 and RootOR was affected by the different irrigant solutions in the root canal; Endo EZE was the most accurate apex locator to estimate the RWL.
\end{abstract}

Keywords: Length Determination; Irrigant Solutions; Apex Locators

\section{Introduction}

The working length is considered the distance between a coronal reference point and an apical level, in order to obtain the instrumentation and obturation limit [1]. This mensuration is one of the main factors in endodontic treatment success [2]. Previous determination of working length is critical to cleaning, shaping and obturation of radicular canals and has to be carefully measured [3].

The use of electronic devices to determine the working length was first proposed by Custer (1918) [4], and the scientific basis of apex locators originated with the investigation by Suzuki, in 1942, that studied the current flow across the teeth of dogs. Consistent values in the electrical resistance between an instrument in a root canal and an electrode in the membrane of the oral mucosa was recorded, and may speculated that this would serve as a measure of the canal length [5]. Sunada (1962) was the first author to describe the details of a simple clinical device for measuring the working length in patients. Since then, electronic apical locators have become an invaluable tool in the practice of modern endodontics [6].

Apex locators may provide more accurate estimation compared to radiographs [7]. In a study which compared the conventional radiograph and the electronic apex locator method (Raypex 5), two blind evaluators concluded that Raypex 5 was superior than the conventional radiographs to determine the working length [7].

The use of irrigant solutions is an important step in endodontic treatment, once these products are fundamentally used to clean and disinfected the root canal [8]. However, these solutions may affect the performance accuracy of apex locators. [9]. evaluated three apex locators (Root ZX, Propex and Neoson EZ) and three irrigant solutions $\left(0.9 \% \mathrm{NaCl}, 3 \% \mathrm{H}_{2} \mathrm{O}_{2}, 2.5 \% \mathrm{NaOCl}\right.$ and $17 \%$ EDTA), and found decreased accuracy of Root ZX and Propex, due to the higher amount of electrolytes; being Neoson EZ the 
most accurate apex locator. [10]. analyzed PROPEX after pulpal excision with three irrigants: $2.5 \% \mathrm{NaOCl}, 0.9 \% \mathrm{NaCl}$ and $0.2 \%$ chlorhexidine gel, demonstrating that the highest discrepancies occurred with $0.9 \% \mathrm{NaCl}$, and the lowest with $0.2 \%$ chlorhexidine gel.

Based on the abovementioned considerations, the objective of this study is to evaluate the accuracy performance of three apex locators using four irrigant solutions to determine the working length of root canals.

\section{Material and Methods}

This study was approved by the Research Ethics Comittee of Norbert Wiener University, by the protocol number 002-2016-CEI. Thirty human premolars were obtained from orthodontic or periodontal reasons, and followed the inclusion criteria: only one root canal, absence of restoration, caries, root cracks, posts or crowns, absence of severe root curvatures, and exclusion criteria: fractured roots, internal or external absortions, opened apex, calcified roots or previous endodontic treatments.

\section{Specimen preparation}

Radiographs were performed in mesiodistal and buccolingual views from all teeth. The specimens were glide path with a K10 file, and planned with a cilindrical diamond bur (MDT, Afula, Israel) in order to obtain a reference point for all the evaluations.

The endodontic access was conducted with a high speed spherical diamond bur (MDT, Afula, Israel). The cervical portion was enlarged with Gates-Glidden burs \# 1, 2 and 3 (Dentsply Maillefer, Ballaigues, Switzerland). The roots were irrigated with $10 \mathrm{ml}$ of saline solution and dried with absorbent papers.

After these previous procedures, teeth were randomly divided in three groups, in order to stabilish the working length, using different apex locators: Raypex 6 (VDW, Munich, Germany); Endo EZE (Ultradent Products, South Jordan, UT, USA); RootOR (MetaBiomed, Korea). To evaluate the working length, an electronic circuit was made with alginate (Jeltrate, Dentsply Maillefer, Ballaigues, Switzerland). The alginate was dispensed in a polymeric matrix, where the specimen was positioned before the alginate gelification. Four different irrigant solutions were used combined with the apex locators: saline solution (0.9\% sodium chloride, Braun, Rio de Janeiro, RJ, Brazil), Chlorhexidine (2\% chlorhexidine digluconate, FGM, Joinville, SC, Brazil), EDTA (18\% Ethylenediamine tetra-acetic acid, Ultradent, South Jourdan, UT, USA) and $4 \%$ sodium hypochlorite (NaClO, Clorox, Lima, Peru). Between measurements, the canals were irrigated with $2 \mathrm{~mL}$ of saline solution and dried with paper points before application of the next irrigant, to remove the previous irrigant completely $[11,12]$.

After the working length mensuration with the apex locators, the real working length (RWL) was determined using a \# $15 \mathrm{~K}$-file (Dentsply Maillefer, Ballaigues, Switzerland) in each specimen until the end of the file was visualized in stereoscopic microscopy (Global, USA). This length was adjusted with a silicon endo stop; the distance between the silicon stop until the end of the file was calculated with a digital calibrator (Stainless Hardened, China). This procedure was repeated three times, and an arithmetic mean was made, determining the RWL.

\section{Statistical Analysis}

Scores (in \%) were attributed to each difference found between the working length gave by the apex locators and the RWL. D Agostino normality test was applied for the data, and t-paired test was used to analyze statistical differences between the RWL and the WL determined by the apex locators, for each experimental group.

\section{Results}

The score distribution showed high differences (between 0.01 and 05) in all groups (Table 1). For the apex locators Raypex 6 and RootOR, the percentages were higher than 1.1, being statistically different from Endo EZE (between 0.51 and 1).

\begin{tabular}{|c|c|c|c|c|c|c|c|c|c|c|c|c|c|c|c|c|c|c|c|c|c|c|c|c|}
\hline & \multicolumn{8}{|c|}{ Raypex 6} & \multicolumn{8}{|c|}{ Endo EZE } & \multicolumn{8}{|c|}{ RootOR } \\
\hline & \multicolumn{2}{|c|}{ sS } & \multicolumn{2}{|c|}{ EDTA } & \multicolumn{2}{|c|}{ CLX } & \multicolumn{2}{|c|}{$\mathrm{NaClO}$} & \multicolumn{2}{|c|}{ ss } & \multicolumn{2}{|c|}{ EDTA } & \multicolumn{2}{|c|}{ CLX } & \multicolumn{2}{|c|}{$\mathrm{NaClO}$} & \multicolumn{2}{|c|}{ SS } & \multicolumn{2}{|c|}{ EDTA } & \multicolumn{2}{|c|}{ CLX } & \multicolumn{2}{|c|}{$\mathrm{NaClO}$} \\
\hline & $\mathrm{N}$ & $\%$ & $\mathrm{n}$ & $\%$ & $\sim$ & $\%$ & $\mathrm{n}$ & $\%$ & $\mathrm{~N}$ & $\%$ & $\mathrm{n}$ & $\%$ & $\mathrm{~N}$ & $\%$ & $\mathrm{n}$ & $\%$ & $\mathrm{n}$ & $\%$ & $\mathrm{n}$ & $\%$ & $\mathrm{n}$ & $\%$ & $\mathrm{n}$ & $\%$ \\
\hline$<-1$ & -- & --- & --- & ---- & 1.0 & 3.30 & --- & ---- & 1.0 & 3.30 & -- & ----- & -- & ---- & 1 & 3.30 & -- & -- & -- & ---- & -- & -- & - & - \\
\hline $\begin{array}{c}-1.0 \mathrm{a}- \\
0.51\end{array}$ & -- & --- & 1.0 & 3.30 & --- & ----- & 1.0 & 3.30 & 2.0 & 6.60 & 1.0 & 3.30 & 3.0 & 10.0 & 3 & 10.0 & 1 & 3.30 & -- & ---- & 1.0 & 3.30 & 2 & 6.60 \\
\hline$-0.5 a-0.0$ & 4.0 & 13.3 & 2.0 & 6.60 & 2.0 & 6.60 & 2.0 & 6.60 & 7.0 & 23.3 & 9.0 & 30.0 & 6.0 & 20.0 & 6 & 20.0 & 6 & 20.0 & 7 & 23.3 & 3.0 & 10.0 & 7 & 23.3 \\
\hline 0.01 a 0.5 & 12 & 40.0 & 14 & 46.6 & 11 & 36.6 & 11 & 36.6 & 11 & 36.6 & 12 & 04.0 & 11 & 36.6 & 9 & 30.0 & 8 & 26.6 & 10 & 33.3 & 13 & 43.3 & 8 & 26.6 \\
\hline 0.51 a 1.0 & 9.0 & 30.0 & 6.0 & 20.0 & 9.0 & 30.0 & 8.0 & 26.6 & 6.0 & 20.0 & 4.0 & 13.3 & 7.0 & 23.3 & 7 & 23.3 & 11 & 36.6 & 6 & 20.0 & 8.0 & 26.6 & 9 & 30.0 \\
\hline$>1.1$ & 5.0 & 16.6 & 7.0 & 23.3 & 7.0 & 23.3 & 8.0 & 26.6 & 3.0 & 10.0 & 4.0 & 13.3 & 3.0 & 10.0 & 4 & 13.3 & 3 & 10.0 & 7 & 23.3 & 5.0 & 16.6 & 4 & 13.3 \\
\hline
\end{tabular}

*SS: saline solution; EDTA: 18\% EDTA; NaClO: 4\% sodium hypochlorite; CLX: 2\% digluconate chlorhexidine

Table 1: Differences distribution (in \%) between the working length determined by the apex locators and RWL, according to the irrigant solutions used.* 
The apex locators Raypex 6 and RootOR demonstrated significant differences between the working length and the RWL. Raypex 6 showed significant differences $(\mathrm{p}<0.001)$ between the irrigant solutions (saline solution: $0.5080 \pm 0.4608$, EDTA: $0.5243 \pm$ 0.5124, Chlorhexidine: $0.5483 \pm 0.5400$, Sodium hypochlorite: $0.5750 \pm 0.5319$ ). For RootOR, differences were also demonstrated $(\mathrm{p}<0.001)$ (saline solution: $0.4300 \pm 0.5326$, EDTA: $0.4257 \pm 0.5788$, Chlorhexidine: $0.5063 \pm 0.5771$, Sodium hypochlorite: 0.3570 $\pm 1.168)$. EndoEZE was the only apex locator which did not showed significant differences $(\mathrm{p}=0.282)$ between the irrigant solutions (saline solution: $0.1973 \pm 0.5774$, EDTA: $0.2820 \pm 0.5055$, Chlorhexidine: $0.2927 \pm 0.5957$, sodium Hypochlorite: $0.1960 \pm 0.7573$ ). These differences are demonstrated in Table 2.

\begin{tabular}{|c|c|c|c|c|}
\hline & SS & NaOCl & EDTA & CLX \\
\hline Raypex 6 & $0.5080 \pm 0.4608 \neq$ & $0.5750 \pm 0.5319 \neq$ & $0.5243 \pm 0.5124 \neq$ & $0.5483 \pm 0.5400 \neq$ \\
\hline Endo EZE & $0.1973 \pm 0.5774=$ & $0.1960 \pm 0.7573=$ & $0.2820 \pm 0.5055=$ & $0.2927 \pm 0.5957=$ \\
\hline RootOR & $0.4300 \pm 0.5326 \neq$ & $0.3570 \pm 1.168 \neq$ & $0.4257 \pm 0.5788 \neq$ & $0.5063 \pm 0.5771 \neq$ \\
\hline
\end{tabular}

${ }^{*}$ SS: saline solution; EDTA: $18 \%$ EDTA; NaClO: $4 \%$ sodium hypochlorite; CLX: $2 \%$ digluconate chlorhexidine. $\neq$ means significant differences, and = means no significant differences between the measurements

Table 2: Mean \pm standard deviation of the differences (in \%) obtained between the working length determined by the apex locators and RWL, according to the irrigant solutions used.*

\section{Discussion}

The first generation of apex locators was based on resistance, differently from the current impedance technology [16]. The main disadvantage of these devices is the poor accuracy in the presence of fluids or blood [17]. The third generation was developed by frequency-base, which showed better precision to estimate the working length, compared to second generation impedance-based apex locators [18].

A recent meta-analysis evaluated the precision of apex locators in determining the RWL. The authors concluded that the device used and the type of irrigation influenced the results [19]. In order to verify the precision of three apex locators, this study showed that the performance of EndoEZE apex locator was not influenced by the irrigant solutions to determine the working length. Similar results were found in the literature [11,12]. The accuracy of RootOR and Raypex 6 was influenced by the use of the four irrigant solutions. [9]. found that accuracy of Root ZX and Propex was decreased, as glass tubules were full of electrolytes. The main reason for the different results may be the parallel glass tubules used, without tapered or constriction, as teeth [9]. In natural anatomy of a permanent tooth, the tubule walls are thicker along its length, and electric properties of glasses are different from human dentine. Also, Ozsezer et al. (10) concluded that Propex was more accurate when the root canal was full of Chlorhexidine, compared to $\mathrm{NaOCl}$ solution. This discrepancy may be attributed to the product concentration $(0.2 \%$ rather than $2 \%)$; the $2 \%$ concentration used in this study is commonly cited in the literature as an effective irrigant solution [8].

The results of this work found there is a significant difference between the RWL and that one found with the apex locators Raypex 6 and RootOR. Saraswathi [20] found similar results with Raypex 5. Differently from our findings, other study showed high accuracy with Raypex 6 [21], even when compared with conventional radiographs [22,23]. demonstrated that RootOR showed an accuracy of $86.7 \%$. In this study, the authors measured the distance from the file tip until the major foramen under stereomicroscopy. Other study showed that RootOR was affected by $2.5 \%$ sodium hypochlorite $(\mathrm{NaOCl}), 0.9 \%$ saline solution $(\mathrm{NaCl})$, and $17 \% \mathrm{EDTA}$. The authors concluded that better results could be found in dry canals [24]. Endo EZE was the only apex locator that did not show differences with the 4 irrigant solutions. This fact may be due to Endo EZE locator reached the apical foramen and the operator should move back $0.5 \mathrm{~mm}$, according to the manufacturer's instructions, which ensures more security to determine the working length. As other authors reported, the operator should retrograde 0.5 to $1 \mathrm{~mm}$ from the indicated position by the apex locators, in order to establish the correct working length [13-15].

The mensurations made with EndoEZE showed that this device gives $100 \%$ of accuraccy ( $\pm 0.5 \mathrm{~mm}$ until the apex foramen), which may be considered an acceptable range [18]. Also, when the canals were irrigated with $4 \%$ sodium hypochlorite, there was a slight difference compared to the other irrigant solutions, maybe because sodium hypochlorite has higher conductivity. These differences were not statistically significant, as the $0.5 \mathrm{~mm}$ range was clinically acceptable.

\section{Conclusions}

The precision to estimate the working length with Raypex 6 and RootOR was affected by the different irrigant solutions in the root canal; Endo EZE was the most accurate apex locator to estimate the RWL.

"The authors declare that there is no conflict of interest regarding the publication of this paper"

\section{References}

1. Ricucci D (1998) Apical limit of root canal instrumentation and obturation, part 1: literature review. Int Endod J 31:384-93.

2. Inoue N, Skinner DH (1985) A simple and accurate way of measuring root canal length. J Endod 11: 421-7.

3. (2003) Glossary of endodontic terms. 7th ed. Chicago: American Association of Endodontists. 
4. Custer LE (1918) Exact methods of locating the apical foramen. J N Dent Associa 5: 815-9.

5. Suzuki K (1942) Experimental study on iontophoresis. J Stomatol Soc (Japan) 16: 411-7.

6. Sunada I (1962) New method for measuring the length of the root canal. J Dent Res 41: 375-87.

7. Ravanshad S, Adl A, Anvar J (2010) Effect of working length measurement by electronic apex locator or radiography on the adequacy of final working length: a randomized clinical trial. J Endod 36: 1753-6.

8. Zender M (2006) Root canal irrigants. J Endodontics 32: 389-98.

9. Fan W, Fan B, Gutmann JL, Bian Z, Fan MW (2006) Evaluation of the accuracy of three electronic apex locators using glass tubules. Int Endo J $39:$ 127-35.

10. Ozsezer E, Inan U, Aydin U (2007) In vivo evaluation of ProPex electronic apex locator. J Endodontics 33: 974-7.

11. Gomes S, Oliver R, Macouzet C, Mercadé M, et al. (2012) In vivo evaluation of the Raypex 5 by using different irrigants. J Endodo J 38: 1075-7.

12. Duran-Sindreu F, Gomes S, St€ober E, Mercade M, Jane L., et al. In vivo evaluation of the iPex and Root ZX electronic apex locators using various irrigants. I Endodo J 46: 769-74.

13. Tselnik M, Baumgartner JC, Marshall JG (2005) An evaluation of Root ZX and Elements Diagnostic Apex Locators. J Endodo 31: 507-9.

14. Wrbas KT, Ziegler AA, Altenburger MJ, Schirrmeister JF (2007) In vivo comparison of working length determination with two electronic apex locators. I Endodo J 40: 133-8.

15. Cianconi L, Angotti V, Felici R, Conte G, Mancini M (2003) Accuracy of three electronic apex locators compared with digital radiography: an ex vivo study. J Endodo 36: 2003-7.

16. Ingle JI, Himel VT, Hawrish CE, Glickman GE (2003) Endodontic cavity preparation. In: Ingle IJ, Bakland LK, editors. Endodontics. 5th ed. Elsevier India: BC Decker 405-570.

17. Kim E, Lee SJ (2004) Electronic apex locator. Dental Clin North America 48: 35-54.

18. Gordon MPJ, Chandler NP (2004) Electronic apex locators. I Endodo J 37: 425-37.

19. Tsesis I, Blazer T, Ben-Izhack G, Taschieri S, Del Fabbro M., et al. (2005) The Precision of Electronic Apex Locators in Working Length Determination: A Systematic Review and Meta-analysis of the Literature. J Endodo 41: 1818-23.

20. Saraswathi V, Kedia A, Purayil TP, Ballal V, Saini A (2016) Comparative evaluation of the accuracy of two electronic apex locators in determining the working length in teeth with simulated apical root resorption: An in vitro study. J Conservative Dentist 19: 402-5.

21. Moscoso S, Pineda K, Basilio J, Alvarado C, Roig M., et al. (2014) Evaluation of Dentaport ZX and Raypex 6 electronic apex locators: an in vivo study. Med Oral Patol Oral Cir Bucal 19: e202-5.

22. Altunbaş D, Kuştarcı A, Toyoğlu M (2017) The Influence of Various Irrigants on the Accuracy of 2 Electronic Apex Locators in Locating Simulated Root Perforations. J Endodo 43: 439-42.

23. Altunbas D, Kustarci A, Arslan D, Er K, Kocak S (2015) Comparison of various current electronic apex locators to determine the working length using the clearing technique. Niger J Clin Pract 18: 359-63.

24. Khandewal D, Ballal NV, Saraswathi MV (2015) Comparative evaluation of accuracy of 2 electronic Apex locators with conventional radiography: an ex vivo study. J Endodon 41: 201-4. 